\title{
1 The role of clusters and public policy in new regional economic path development
}

\author{
Bjørn T. Asheim, Arne Isaksen, Roman Martin \\ and Michaela Trippl
}

\subsection{INTRODUCTION}

Among the many ideas and concepts that have their intellectual roots in economic geography, 'clusters' have certainly been among the most influential ones on regional policymaking. Clusters have become a standard regional policy approach, and policymakers and practitioners around the world have seized upon clusters as a tool for promoting regional competitiveness, innovation and growth. Even though the cluster concept has been interpreted in different ways and a standardized cluster policy approach does not exist (Enright 2003; Kiese 2005), most cluster policies focus on efficiency gains through sectoral specialization and the further strengthening of existing regional strongholds. Such a policy approach is well suited to support regional path extension, but reaches its limit when the objective is to initiate and nurture new development paths. Not surprisingly, there are only few successful cases where cluster policies have led to the renewal and transformation of declining clusters, let alone the creation of entirely new ones (Koschatzky 2012).

The literature on path dependence and regional economic evolution shows that regional development is far from a smooth process, but rather is subject to all sorts of disruptions and discontinuities (Martin and Sunley 2006). In order to remain competitive, regional economies need to adapt continuously to changing global economic conditions. Industries and clusters that were prosperous in the past can lose their competitiveness, which may result in regional economic crisis and decline (Simmie and Martin 2010). It is therefore important that regional policymakers implement strategies that not only lead to a reinforcement of existing regional structures, potentially leading to negative lock-in, but also to the rise and further development of new growth paths (see, for instance, Morgan 2013). 
In this chapter, we show that clusters can be a suitable concept and policy tool not only to foster path extension, but also to achieve path renewal and new path creation if embedded in a wider regional development strategy.

The current debate on regional development strategies is (at least in the European and OECD countries) heavily dominated by smart specialization (S3), a strategic approach to innovation-based regional growth (EC 2012; OECD 2013a; Landabaso 2014). Even though S3 is of significant importance for policymakers all over Europe (EU member states have to design and implement this strategy in order to receive structural funds), it remains subject to a range of different interpretations. The conceptual ambiguity is partly due to the choice of key words that can easily lead to false interpretations, notably the notions of 'specialization' and 'entrepreneurial discovery'. First, rather than promoting sectoral specialization, smart specialization refers to regional diversification into areas related to current regional strengths. Second, rather than focusing on firm-driven entrepreneurship, entrepreneurial discovery is thought of broadly as encompassing all actors of a triple-helix constellation that can potentially contribute to discovering current and future areas of regional competitiveness. S3 is thereby very close to the idea of Constructing Regional Advantage (CRA), a theoretically informed policy approach that brings together concepts such as related variety, knowledge bases and policy platforms to promote innovation-based regional development (Cooke et al. 2006; Asheim et al. 2011). CRA emphasizes a proactive role of public-private partnerships in promoting innovation through a customized approach to regional development, appreciating the industry-specific modes of innovation and knowledge bases on which these innovation modes build. As we will show in this chapter, the CRA approach offers a sound theoretical basis to study the role that policy can play for new regional economic path development.

This book chapter is organized as follows. Section 1.2 discusses the cluster concept and recent accounts on long-term cluster evolution. While cluster polices have a tendency to foster path extension, new path development requires a broader policy strategy that promotes regional diversification and knowledge combinations, as advocated by the CRA approach described in Sections 1.3 and 1.4. The empirical analysis provided in Sections 1.5 and 1.6 underlines the role of public policy for new path development. While the new media cluster in southern Sweden is an example of path renewal through combining knowledge bases, the Oslo Cancer Cluster is an example for new path creation based on scientific knowledge. Section 1.7 concludes with a discussion of the differentiated role that clusters and public policy can play in new path development. 


\subsection{CLUSTER EVOLUTION AND POLICY}

Clusters have become a key concept for researchers and policymakers dealing with regional economic development. Even though there is no commonly agreed definition of clusters (Martin and Sunley 2003), most scholars refer to clusters as geographical concentration of firms that are active in a particular field and interconnected through patterns of cooperation and knowledge exchange (see, for instance, Porter 1998: 78; Van den Berg et al. 2001: 18). While the term 'cluster' was popularized by Michael Porter $(1990,1998)$ the academic origins of the concept refer back to Alfred Marshall's (1890) early work on industrial districts and the ideas developed by economic geographers ever since.

Central to the cluster concept is the idea that firms gain advantage not only from internal economies of scale, but also from external economies that result from co-location with other, similar firms (that is, localization economies). For Marshall, these localization economies are the outcome of 'the concentration of specialised industries in particular localities' (1890: 222) and are linked to three types of benefits, namely the availability of skilled labour in a region, the growth of supporting and auxiliary trades, and the specialization of firms in diverse stages and branches of production. By locating in an industrial district, firms can take advantage from local factor endowments, and can reap additional benefits from knowledge that is 'in the air' and travels intentionally or unintentionally between firms. Marshall's arguments are still very much persistent in current theories on spatial clustering (Martin and Sunley 2003; Asheim et al. 2006). Today, cluster advantages are usually understood as ready access to a local pool of skilled labour, specialized service providers and adapted local infrastructures, as well as knowledge flows between innovative firms, universities and research and development (R\&D) organizations in a given region. While the cluster concept does not negate the advantages that result from industrial diversity (that is, urbanization economies), it is fair to say that it heavily emphasizes sectoral specialization and interaction between related firms as key to regional competitiveness and growth. Consequently, most cluster polices are designed to reinforce current regional strongholds and to further specialize on already existing industries (Enright 2003; Koschatzky 2012).

While the literature on clusters has so far been mostly concerned with analysing the mechanisms behind spatial clustering and the reasons why clustered firms gain competitive advantage over non-clustered ones, less attention has been devoted to the question of how clusters develop over time (Lorenzen 2005; Bergman 2008; Isaksen 2011; Boschma and Fornahl 2011). This question calls for an evolutionary perspective that focuses on 
long-term cluster dynamics. Different theoretical approaches to cluster evolution are discussed in the literature, many of which are inspired by basic product life cycle theory and later studies of industry life cycles (see, for instance, Bergman 2008; Menzel and Fornahl 2010; Martin and Sunley 2011). They argue that cluster evolution follows a cyclical development with sequential phases of emergence, growth, decline and renewal. Firm entries and exits, industry heterogeneity, external economies of scale as well as openness or rigidity of inter-firm networks are central explanations for the transition from one stage of cluster evolution to another. Protagonists of these models emphasize that the implied cyclical development should not be seen as predetermined (Martin and Sunley 2011). Clusters have unique characteristics and are embedded in a wider geographical context, which affects their development. Cluster evolution follows different path dependencies (Belussi and Sedita 2009; Strambach and Klement 2013), is subject to actions taken by human agents, enabled or constrained by institutional arrangements and sociocultural settings, and affected by governmental initiatives and political agendas on multiple geographical scales (Isaksen 2011; Martin and Trippl 2015; Trippl et al. 2015).

In this chapter, we study cluster evolution from an institutional perspective that focuses on changes in the wider regional innovation system, including firms, universities and governmental agencies (Braczyk et al. 1998; Asheim and Gertler 2005). Such a systemic perspective on cluster evolution allows us to shed more light on the role that public policy can play in regional development. We argue that new path development (that is, path renewal and path creation) requires a broad-based policy approach that stimulates cross-fertilizing effects between different economic activities within and beyond the region. While cluster policies are well suited to support the growth and sustainment of existing industries, policies for new path development should aim at regional diversification and variety creation, preferably based on existing strengths and expertise in the region. This idea of regional diversification is central to the Constructing Regional Advantage (CRA) approach (Cooke et al. 2006; Asheim et al. 2011), which is described in the following section.

\subsection{CONSTRUCTING REGIONAL ADVANTAGE AS POLICY STRATEGY FOR NEW PATH DEVELOPMENT}

Constructing Regional Advantage refers to promoting competitive advantage through product differentiation creating unique products. While building on the lessons from the dynamic principle of the theory of 
competitive advantage (Porter 1998) as well as of the innovation systems approach (Lundvall 2008) emphasizing that competitiveness can be influenced by innovation policies and supporting regulatory and institutional frameworks, the constructed advantage approach especially recognizes the role of a proactive public-private partnership and the impact of the public sector and public policy support by acknowledging to a greater extent the importance of institutional complementarities in knowledge economies. This approach represents an improved understanding of and response to the problems of system failures caused by a lack of connectivity in regional innovation systems (Martin and Trippl 2014; Isaksen and Trippl 2016).

Increasingly there is strong agreement that innovation is the key factor in promoting competitiveness in a globalizing knowledge economy. Competition based on innovation implies choosing the high-road strategy, which is the only sustainable alternative for developed, high-cost regional and national economies as well as for the future of developing economies. For a long time such a strategy was thought of as being identical with promoting high-tech, R\&D-intensive industries in accordance with the linear view of innovation. But more and more the recognition has evolved that a broader and more comprehensive view on innovation has to be applied to retain and develop competitiveness in the heterogeneity of European regions; that is, that all drivers of innovation - both supply and demand side (user, market, demand (social innovation)) as well as employee-driven innovation - have to be integrated into an overall approach to innovation policy. This broad, comprehensive view requires a differentiated perspective on the types of knowledge relevant in innovation processes (Asheim and Gertler 2005; Asheim 2007). Such a broad-based innovation policy is in line with the innovation system approach of defining innovation as interactive learning combining an STI (science, technology, innovation) and a DUI (doing, using, interacting) mode of innovation (Lorenz and Lundvall 2006). This approach also appreciates the heterogeneity of European regions, thereby avoiding a 'one size fits all' approach (Tödtling and Trippl 2005).

Thus, a Porter perspective was adopted arguing that all industries can be innovative and that the high-tech-low-tech distinction is not relevant at a sectoral level as a point of departure for innovation policies, as R\&D intensity is not the same as innovation capacity; knowledge is a far broader concept than R\&D. This implies that regional advantage has to be constructed on the basis of the uniqueness of the capabilities of firms and regions, which, however, in a globalizing economy becomes more and more knowledge intensive (Asheim et al. 2006). Second, it implies that regions and countries should base their competitive strategy on industries they traditionally have been doing well in; that is, building on their technological 
path dependency to achieve positive lock-in effects or path extension. The existing industrial structure of regions will also in most cases represent the main source of path renewal in the form of regional branching based on related variety to secure future competitiveness and to make regions resilient (Boschma 2015).

Knowledge processes have become increasingly complex in the globalizing knowledge economy. The binary argument of whether knowledge is codified (that is, knowledge that has been stored in certain media and can readily be transmitted to others) or tacit (that is, knowledge that is difficult to transfer to another person by means of writing it down or verbalizing it) becomes too simplistic to accommodate this increased complexity and provide an adequate understanding of knowledge creation, learning and innovation. Thus, a need to go beyond this simple dichotomy can be identified. One way of doing this is to make a distinction between 'synthetic', 'analytical' and 'symbolic' types of knowledge bases, which partly transcends the tacit-codified dichotomy arguing that the two forms of knowledge always coexist but in different combinations, and partly emphasizes that all types of economic activity can be innovative but that the modes of innovation differ, thus transcending the high-tech-low-tech dichotomy (Martin and Moodysson 2013). As this threefold distinction refers to ideal-types, most activities are in practice comprised of more than one knowledge base. New combinations of knowledge bases, especially when symbolic knowledge is involved, seem to become increasingly important as a source of new path development.

An analytical knowledge base refers to economic activities where scientific knowledge based on formal models and codification is highly important. Examples are biotechnology and nanotechnology. Universityindustry links and respective networks are more important than in the other types of knowledge bases. Knowledge inputs and outputs in this type of knowledge base are more often codified than in the other types. The workforce, as a consequence, more often needs some research experience or university training. Knowledge creation in the form of scientific discoveries and (generic) technological inventions is more important than in the other knowledge types, and consequently innovations are science-driven. Partly these inventions lead to patents and licensing activities. Knowledge application is in the form of new products or processes, and there are more radical innovations than in the other knowledge types. An important route of knowledge application is new firms and spin-off companies that are formed on the basis of radically new inventions or products.

A synthetic knowledge base refers to economic activities, where innovation takes place mainly through the application or novel combinations of existing knowledge. Often this occurs in response to the need to solve 
specific problems coming up in the interaction with customers and suppliers, and thus innovations are user-, market- and demand-driven. Industry examples include plant engineering, specialized advanced industrial machinery and shipbuilding. University-industry links are also important for this knowledge base, but more in the field of applied research and development than in basic research. Tacit knowledge is more important than in the analytical type, in particular due to the fact that knowledge often results from experience gained at the workplace, and through learning by doing, using and interacting. Compared to the analytical knowledge base, there is more concrete know-how, craft and practical skills required, which is provided by technical universities, polytechnics or by on-the-job training. Overall, this leads to a rather incremental way of innovation, dominated by the modification of existing products and processes.

Symbolic knowledge is related to the creation of meaning and desire as well as aesthetic attributes of products, such as designs, images and symbols, and to its economic use. The increasing significance of this intangible type of knowledge is observed by the OECD (2013b) mentioning, for example, design as a new source of growth as part of firms' knowledgebased capital as well as through the dynamic development of cultural production such as media (film-making, publishing and music), advertising, design, brands and fashion. In cultural production, the input is aesthetic rather than cognitive in quality. This demands rather specialized abilities in symbol interpretation and creativity. This type of knowledge is often narrowly tied to a deep understanding of the habits and norms and the 'everyday culture' of specific social groupings. Due to the cultural embeddedness of interpretations, this type of knowledge base is characterized by a distinctive tacit component and is usually highly context-specific. The acquisition of essential creative, imaginative and interpretive skills is less tied to formal qualifications and university degrees than to practice in various stages of the creative process; however, this knowledge base has also become increasingly more knowledge-intensive.

The knowledge base approach implies that no type of knowledge should a priori be classified as more advanced, complex and sophisticated than other knowledge (Laestadius 2007), or that analytical knowledge be considered more important for innovation and competitiveness of firms, industries and regions than synthetic or symbolic knowledge. The knowledge base approach thus offers a promising framework for informing the next generation of broad-based regional innovation policy; that is, being able to fine-tune regional innovation policy according to the dominating knowledge bases in the region both with respect to strengthening existing industries and promoting new path development. This implies an active role of policymakers and agencies in stimulating novel combinations of 
differentiated knowledge bases, thereby boosting innovation and regional development (Asheim et al. 2011). The OECD highlights knowledge-based capital (KBC), constituted precisely by combining knowledge bases, as new sources of growth (OECD 2013b).

\subsection{NEW REGIONAL ECONOMIC PATH DEVELOPMENT}

When designing and implementing a policy strategy for regional development, it is necessary not only to consider how to secure 'path extension' by promoting existing clusters, but also to stimulate new path development (that is, path renewal and path creation) by supporting the emergence of new clusters.

Path extension mainly results in incremental product and process innovations in existing industries and technological trajectories. While this can secure competitiveness and growth in a short- and medium-term perspective, in the longer run these industries run the risk of path exhaustion, referring to situations where the capacity for renewal is lacking. Path renewal takes place when existing local firms branch into different but related activities and sectors. Regions' industrial specialization and firms' knowledge bases shape the types of renewal that occur in the form of regional branching (Boschma and Frenken 2011). Path creation represents the most wide-ranging changes in a regional economy. It includes the establishment of new firms in new sectors, or firms that introduce new products, processes and/or business models in the regional economy. Path creation is most often R\&D-driven and can either be the result of knowledge-based entrepreneurial discovery (university spin-offs through commercialization of research results) or proactive regional innovation policy aiming at constructing regional advantage, as is the goal of VINNOVA's (Swedish Governmental Agency for Innovation Systems) Centre of Expertise programmes (Asheim et al. 2011, 2013; Isaksen and Trippl 2016).

The main problem of traditional industries with respect to promoting new path development (path renewal) and making them more innovative and competitive is the low educational and competence level and a lack of investment in R\&D. This implies that these firms and industries have a low absorptive capacity, which limits their capacity to access and acquire new and often external knowledge, make use of new production equipment and penetrate new markets, especially international ones. It also handicaps them in approaching universities to make their knowledge more researchbased and/or informed, which would extend their mode of innovation to the STI type. What is needed is to build absorptive capacity of DUI-based 
firms by increasing their research-based competence (Isaksen and Nilsson 2013). This is an important strategy for the upgrading of traditional industries, as research has demonstrated that combining DUI and STI makes firms perform better by utilizing both analytical and synthetic knowledge bases (Jensen et al. 2007).

Another strategy of upgrading of traditional industries is to move into high value-added niches. This is a strategy that can be realized most efficiently by mobilizing the symbolic knowledge base, often in combination with synthetic knowledge, and by applying a platform approach - that is, transcending traditional sectors - in the concrete design and implementation. This would normally imply that the firms continue to rely on the DUI mode of innovation, but are able to climb the value-added ladder by introducing new products that have a high element of symbolic knowledge to achieve product differentiation and thus represent a unique product at the high-end of the global market.

The two empirical examples in this chapter illustrate the two alternative ways clusters can contribute to a regional diversification process: the new media cluster in Malmö as an example of path renewal by combining knowledge bases in a related variety way, and the Oslo Cancer Cluster exemplifying new path creation by the commercialization of discoveries from basic research at universities and university hospitals.

\subsection{THE RISE AND FURTHER DEVELOPMENT OF THE NEW MEDIA CLUSTER IN SOUTHERN SWEDEN: THE ROLE OF POLICY}

Since its rise in the early 2000s, the new media cluster in Scania, Sweden's most southern county, has grown to a considerable size. As of 2015, the cluster hosts several hundred small and medium-sized firms, as well as strong knowledge and support organizations.

The new media industry covers a range of activities related to media content (for example, text, graphics, music, video) and modern information and communication technology (for example, computer, mobile phones, tablets) (Lievrouw and Livingstone 2002). Examples in the case of Scania are the development of computer games, various software applications for smartphones and other mobile devices, film and TV, as well as digital design and advertising. What these activities have in common is that they all have strong symbolic components as regards their innovation outcomes and that they all draw on artistic skills as an important supplement to competences that are more technical. In the new media industry, innovation is typically organized in short-term projects involving a range 
of different collaboration partners, including small firms and freelancers, often located in close geographical proximity (Cooke 2002; Grabher 2002).

The following analysis of the new media cluster in Scania draws on a combination of document studies and in-depth interviews with key stakeholders. In addition to 37 interviews with business representatives conducted in 2008-2009, 16 interviews with policymakers, industry experts and cluster managers were carried out in 2012-2013.

\subsubsection{The Early Roots and Rise of the Cluster}

The rise of the new media cluster in Scania can be traced back to the beginning of the past decade. At that time, Scania faced the challenge to undergo a fundamental regional transformation process by nurturing new growth paths. At the turn of the millennium, Scania still suffered from a downturn and loss of its traditional industries such as shipbuilding and heavy machinery. At the same time, Scania's ICT cluster - which emerged at the beginning of the 1980s and has been dominated by large companies relying on analytical and synthetic knowledge bases (Ericsson, Swedish Telekom) - was hit hard by the global IT crisis. The subsequent restructuring of the ICT cluster led to lay-offs of skilled engineers and scientists in the region (Martin and Trippl 2015). Therefore, the need to renew the ICT cluster and to grow new clusters to compensate for the decline of old sectors was strong.

New media and digital design were among the new niches with a remarkable future growth potential in Scania. As shown below, the rise and further development of the new media cluster clearly demonstrates that clusters are amenable to policy influence. Two early policy actions included the conversion of Malmö's old industrial and harbour area into a modern business and housing district, which today houses the majority of new media firms, and the foundation of a new university college in Malmö. The rise of the new media cluster is, indeed, inextricably linked to the establishment of Malmö University in 1998. In particular the foundation of the School of Arts and Communication (K3) at Malmö University proved to be important, securing at a very early stage the provision of highly skilled workers for the emerging cluster. K3 focused its study programmes in fields such as interaction design, graphical design, media and communication, performing arts and culture, which are among the cluster's core strengths today. The establishment of $\mathrm{K} 3$ has contributed in a variety of ways to the emergence and further development of the new media cluster. Not only has it provided the cluster with skilled graduates and enhanced Scania's symbolic knowledge base, but our interviews with former decision-makers in the local and regional government also suggest that $\mathrm{K} 3$ was crucial in 
helping raise awareness among key policy actors of the growth potential of design and creative industries. From 2000 onwards they have, in close interaction with other key stakeholders in the region, designed and implemented a series of policy actions supporting the emergence and dynamic growth of the new media cluster in Scania.

In 2002, regional and local policy bodies (Region Skåne and Malmö Municipality) provided funding for the project M-Town, which can be seen as an early attempt to stimulate knowledge flows across industries and to combine different but related industrial activities. More precisely, M-Town's aim was to create linkages between companies operating in the telecom, internet/IT, media and entertainment sectors (TIME industry). M-Town thus reflected a shift away from a sectoral logic towards a policy approach in which emphasis was put on inter-industry crossovers, much in line with recent academic insights into the importance of related variety, combinations of knowledge bases and platform policies (Asheim et al. 2011).

The project M-Town was launched as a response to the shock caused by the collapse of the IT bubble at the beginning of the past decade. The ambition behind M-Town was to enhance knowledge flows between newly founded and incumbent firms in the ICT sector, and to create connections to the media and entertainment sector (for example film, TV, radio), a combination that was considered a promising future business area. Even though the project turned out to be too ambitious at that time, M-Town played a key role as pilot project, paving the way for proactive cluster policies in the field of new media in the following years.

\subsubsection{Further Development of the Cluster}

In 2004, the regional cluster initiative Media Meeting Place Malmö (MMM) was established. MMM was the outcome of a joint effort by local and regional policy bodies (Malmö Municipality and Region Skåne), seizing funding opportunities at the national level. At that time, the promotion of design and creative industries ranked high on the policy agenda of various national ministries and funding agencies such as the Ministry of Industry, the Swedish Agency for Economic and Regional Growth and the Knowledge Foundation (KK). KK played a particularly important role, providing funding for eight 'meeting places' for creative industries in various Swedish regions. A close interaction between industry, academia and government (that is, triple-helix constellations) and a high potential for linkages between creative industries and related sectors existing in the region were among the key preconditions for receiving funding from KK (Heed et al. 2008). Scania's initial conditions were favourable, including 
a growing number of new media firms, Malmö University with its focus on media and design, as well as a local and regional government that had already shown its commitment to the promotion of new media by initiating the project M-Town. Furthermore, the region's strengths in ICT proved to be a key asset, as new media activities typically combine creative design with ICT technology, which was in line with KK's cross-sectoral focus. Drawing on these advantages, Scania's application for funding was successful and the cluster initiative MMM received financial support from KK for a five-year period. In addition to the promotion of networking that formed the core policy approach of MMM, the cluster's organizational support structure was further strengthened. Malmö Municipality established a business incubator (Malmö Incubator, MINC), situated in close vicinity to Malmö University. MINC was founded in 2003 and hosts a number of start-up companies mostly operating in the field of new media.

By the end of the past decade, the cluster initiative MMM already had more than 70 members (Martin and Moodysson 2011). National funding expired in 2009 but was soon replaced by EU funds attracted by a consortium consisting of public and private actors. More precisely, Region Skåne, Region Blekinge, Malmö Municipality, Helsingborg Municipality, Malmö University and a number of private firms applied for money from the EU structural funds to secure the continuation of the cluster initiative for another three years. The dynamic development of the cluster and the long-term commitment of local and regional policy agencies formed the basis for the decision of EU authorities to provide $€ 1.24$ million financing. The cluster initiative has been renamed Moving Media Southern Sweden (MMSS) and received co-financing by the aforementioned public-private consortium. Key policy actions to promote cluster development included again the facilitation of regional networking and knowledge exchange, which is considered as eminently important for clusters that rely on a symbolic knowledge base (Martin and Trippl 2014). Around the same time, a new research and innovation centre for digital media (MEDEA) was established at Malmö University. Partly financed by EU structural funds, the creation of MEDEA has further enhanced the cluster's research capacity and facilitated knowledge exchange between Malmö University and new media firms in the region.

One of the most recent policy actions was the establishment of the large business park Media Evolution City (MEC) for new media firms in Malmö’s Western harbour area by Region Skåne and Malmö Municipality. MEC opened its doors in 2012 and as of today it houses more than 100 firms. Over recent years, more and more firms have joined the cluster initiative (now renamed Media Evolution, ME) as member organizations. With the dynamic development of the new media industry in Scania, 
financial engagement by the private sector in the cluster initiative increased significantly. Today, the cluster initiative has around 350 members, reflecting both the success of ME and the growth of the industry in the region.

\subsection{THE EMERGENCE OF THE OSLO CANCER MEDICINE CLUSTER: THE ROLE OF POLICY}

A number of highly research based firms focusing on cancer diagnostic, treatment and medicine have emerged in Oslo since the late 1990s (Skålholt and Thune 2013). The firms have become part of a cluster organization named Oslo Cancer Cluster (OCC). The organization received the status of Norwegian Centre of Expertise by Innovation Norway in 2007, a status reserved for internationally competitive clusters in Norway.

OCC includes about 20 knowledge and support organizations of different types and about 40 biotechnology firms. Nearly half of the firms are Norwegian divisions of often very large pharmaceutical multinationals, which are among the dominant global players within the industry. These divisions represent the bulk of more than 2,000 jobs among members of OCC (Furre and Flatnes 2013). However, the cluster also includes just over 20 younger, independent and mostly small pharmaceutical firms. These are most often academic spin-offs but also industrial spin-offs or start-up companies with Norwegian entrepreneurs and venture capital. The firms are mostly still in the clinical test phases of their first products or occupied with developing further a technological platform. Norwegian firms mainly develop cancer drugs in clinical phase I and II in Norway. In phase III, these small firms often need to cooperate with international pharmaceutical companies due to high development costs and lack of patient volunteers in Norway to carry out phase III testing. A few Oslo-based firms have put patent protected products on the market under their own brand name or have licence agreements with global biotechnology companies. Furre and Flatnes (2013) actually demonstrated that the number of jobs and value creation decreased somewhat among member firms in OCC between 2004 and 2011 due to reduction of back-office functions in the Norwegian divisions of multinationals that was not offset by growth in new, Oslo-based firms.

\subsubsection{The Historical Roots of the Cluster}

The new and small cancer medicine firms rely on highly specialized analytical knowledge related to cancer. The systematic development of this knowledge started when a special hospital for cancer treatment (the 
Radium Hospital) was established in Oslo in 1932 as one of the first specialized hospitals for cancer treatment in the world. The hospital had no state funding at the start, but was financed by fundraising activities, contributions from the Norwegian Cancer Society and also significant private gifts (Skårderud 2007). The hospital has been the centre for long-term development of knowledge, which is described in this way in a review of the hospital's history: 'It has almost been an indisputably claim that newly hired assistant doctors are expected to take a PhD. It is been implied that one does not necessarily go home after normal working hours' (Skårderud 2007: 204, translated by A. Isaksen).

Further knowledge organizations emerged. First, a cancer register aimed at registering and monitoring the development of cancer in Norway was established in 1952. The register was financed by private funds until the state took over the responsibility in 1979. All medical doctors in Norway are instructed by law to notify new cancer cases to the Cancer Register. The large amount of data and the unique personal identification number in Norway make the Cancer Register's data suitable for research both nationally and internationally. Second, a Cancer Research Institute for basic research, clinical research and method development was established in 1954 (Skårderud 2007). It started as an independent entity, backed by the state-owned Norwegian company Hydro, and has since its start been central in Norwegian and international cancer research, and Norway has comparatively many scientific publications within cancer research (oncology) (Reve and Sasson 2012). A few other R\&D institutes and higher education institutions also developed relevant scientific knowledge. Among these is the Centre for Cancer Biomedicine, which is a research institute focused on cancer research with about 100 employees located at the University of Oslo and Oslo University Hospital.

\subsubsection{Academic Entrepreneurship}

The research at the Radium Hospital and related organizations has been a vital source of analytical knowledge for new cancer drug firms (Nicolaysen 2013: 71). The R\&D institutes and higher education institutions are important when it comes to providing employees, performing research, as sources of several spin-off firms and, not least, by 'creating' potential entrepreneurs with scientific knowledge that are vital for starting new firms focused on developing cancer drugs. Ten of 12 Norwegian-owned firms in the OCC (that answered questions about the background of their founders) were started by individual entrepreneurs, the two others by a venture capital fund and existing firms. The ten firms have 21 entrepreneurs, and virtually all of these have a PhD. In nine of the 12 firms, the core competence originates 
from research carried out by the entrepreneurs at the Radium Hospital, in some cases in cooperation with researchers at Oslo University Hospital, the University of Oslo and the Norwegian firm Hydro.

Some of the founders are serial entrepreneurs. Algeta was established in 1997 by a doctoral student who also was a researcher at the Radium Hospital's lab, and his supervisor who was a professor at the University of Oslo. Algeta entered a partnership agreement with Bayer Schering Pharma AG in 2009 regarding the development and commercialization of Algeta's first product candidate, which was in phase III of clinical testing (Vesterbekkmo 2010). Algeta was acquired by Bayer for 17.6 billion NOK (about $€ 2$ billion) in 2014. The founders of Algeta established two new firms in 2009 and 2010 together with one and two other researchers, respectively. In two more cases entrepreneurs have established one additional firm. One of these is a spin-off from Photocure, which is one of the few Norwegian-owned pharmaceutical firms with marketed products and world leadership in a specific technology. Photocure also originated from the Radium Hospital in 1997.

\subsubsection{New Policy Tools and Knowledge Combination}

A strong and specialized analytical knowledge base is key in starting highly research-intensive firms such as the cancer drugs firms in Oslo. Scientific knowledge is, however, not a sufficient condition on its own. The knowledge has to be turned into commercial use if a number of new firms and a cluster are to emerge.

Two regulatory changes in Norway from 2003 improved the conditions for research-based start-ups. A new law on employee inventions in Norway in 2003 meant that employers could claim the right to inventions made by workers, while previously the employees themselves held the rights to results and inventions that could be commercialized. The University and University College Law from 2003 also includes a duty for these organizations to provide for the application of research results in industry.

The new legislation imposes on us to help ensure that research results are used for product development. This marks to some degree a limit in that we from now as an institution are obliged to consider the potential of research results. The University will now have to establish internal expertise and capacity to deal with the new situation. (Interview with then-rector of the University of Oslo in the university's research magazine Appolon released on 1 January 2003, translated by A. Isaksen)

The changes contributed to the build-up of stronger commercialization units at the University of Oslo and the Radium Hospital, and 
it strengthened cooperation on commercialization among other public actors such as Innovation Norway, private actors such as the Radium Hospital Research Foundation and the knowledge organizations responsible for commercialization of a new idea (Nicolaysen 2013).

The regulatory changes contributed to transforming the large capacity of cancer research in Oslo into a regional research and commercialization system. The transformation is seen in the establishment of new organizations and in the development of experience-based competence in commercialization. Six fairly recently established seed and venture capital funds are part of the commercialization system. Included here is Innovation Norway, which is the government's most important instrument for innovation and the development of Norwegian firms. The other funds are focused on supporting academic spin-offs and on life science start-ups. Inven2 is the largest actor within the commercialization of research in Norway, owned by the University of Oslo and Oslo University Hospital and particularly occupied with innovations from these organizations. A similar fund is the Norwegian Radium Hospital Research Foundation (NRHR), which is a pre-seed investor and project developer, aimed at strengthening cancer research at the Radium Hospital and also at investing in companies based on other leading Nordic research institutes. In mid-2012, the NRHR had invested in 13 companies with a total stock value of more than 200 million NOK (about $€ 27$ million). Experienced entrepreneurs maintain that these capital funds have clearly improved the access to risk capital compared to the 1990s (Nicolaysen 2013).

The new cancer drug firms in Oslo are small and dependent on cooperation with and knowledge from hospitals, research institutes, capital funds, industry and different specialists, and on recruiting skilled workers. The OCC includes four contract research organizations, for example, which provide a range of support, such as running clinical trials and developing documentation for products, to the pharmaceutical and biotechnology industries in the form of research services outsourced on contracts. Cooperation with many specialists and meetings are easier to organize when people are in geographical proximity.

Another important triggering factor for the emergence of the Oslo Cancer Cluster is the creation of business expertise about firm startup, clinical testing and contact with large pharmaceutical companies. Important business expertise was created and spread to entrepreneurs when the large Norwegian industrial company Hydro built up a pharmacy department from the late 1980s. Pharmacy was thought of as one of several new activity areas in the diversification strategy of Hydro (Lie 2005). Hydro Pharma was established in 1986 and grew fast during the following years through acquisitions. Its research centre (located in Porsgrunn about 
160 kilometres from Oslo) discovered a substance that might possibly affect cancer cells and started collaborating with researchers at the Radium Hospital. Hydro 'also had a number of scouts who visited research centres where people could show their projects. I presented two projects which the scouts liked very much' (entrepreneur of two cancer-related firms in Oslo, interview spring 2013). Hydro Pharma focused for a few years on the development of a cancer remedy, but the initiative failed when a clinical trial did not provide demonstrable positive results (Lie 2005: 255). Hydro left the pharmaceuticals sector in 1993, because the company's strategy changed to concentrate on its traditional core areas of energy-intensive activities.

Hydro's initiative is still seen by several key persons in the Oslo Cancer Cluster as very important for the evolution of the cancer drug industry in Oslo. First, some firms have developed further projects and knowledge originally created in the 1990s in collaboration between Hydro and the Radium Hospital. There are cases in which patients that took part in clinical studies in the 1990s lived longer than patients who were not part of the studies, which are results that initiated further research on the original remedies. Second, Hydro contributed with industry experience, as did former employees of a few large Norway-based pharmaceutical companies such as Nycomed Amersham. Some have been involved in several start-ups and product developments and have acquired business experience and skills in the development of pharmaceutical products. People with industrial experience were hired or employed in start-up firms and passed on industrial and commercial knowledge to start-ups (Nicolaysen 2013). The shortterm focus on pharmaceuticals in Hydro contributed to a combination of knowledge bases in the Oslo cancer industry when the analytical knowledge of researchers was mixed with the synthetic industry and business expertise coming from Hydro and a few former successful pharmaceutical companies in Oslo.

\subsubsection{The NCE Status}

General policy tools stimulated the emergence of a cluster of firms focused on cancer diagnostic and treatment in Oslo until 2007. Important were public research grants for cancer research and funds targeting increased commercialization of research results, including supporting spin-off firms. Specific cluster-building policy tools were introduced when the Oslo Cancer Cluster organization became part of the Norwegian Centre of Expertise (NCE) programme in 2007. The NCE programme was launched in 2006 by Innovation Norway with the aim of strengthening innovation and internationalization processes further in already strong regional 
clusters, and where the members of the cluster organizations agree to enter binding collaboration agreements (Isaksen 2009).

The NCE programme has a long-term perspective. The participating clusters are offered professional and financial support for development processes up to ten years. Regional cluster projects have to apply for membership. The criteria for membership are quite restricted, and there is intense competition to become a member. Local/regional actors have to establish a partnership (or use an already existing partnership) of relevant players to form an application. The application must be embedded in the most important firms in the region, in knowledge organizations such as universities, higher education and other R\&D organizations, public support organizations and financial actors.

The NCE project has led to an improved R\&D structure for the OCC member firms (Furre and Flatnes 2013). This includes faster financing of new firms, the development of an incubator focused on cancer drug firms, help with obtaining a large research project financed by the Research Council of Norway, and the establishment of Oslo Cancer Innovation Park. The membership has widened to include the whole cancer diagnostic sector in Norway and global partners, but with still a strong core of firms and research institutes in Oslo.

\subsection{CONCLUSION}

To summarize, the rise and development of the new media cluster in Scania has been essentially influenced by a variety of policy actions. Among the most important ones are the investment in infrastructure (conversion of the old harbour area into a modern business and housing district), the continuous strengthening of the cluster's organizational support structure (foundation of Malmö University and K3, establishment of MINC, creation of a new research and innovation centre for digital media) and a longterm cluster initiative. The latter is particularly interesting, as it reflects a very early adoption (or anticipation) of ideas emanating from academic research on related variety, combinations of knowledge bases and crossindustrial knowledge flows. Furthermore, it demonstrates the importance of active policy intervention consisting of concerted, long-term efforts to promote cluster development. The explicit ambition by local and regional authorities to strengthen the region's symbolic knowledge base and to combine it with the more established analytic and synthetic competences in the region can be regarded as a forward-looking and prospective approach in the early 2000s. The case of new media in Scania provides also insights into public-private partnership approaches to cluster governance. The 
design and implementation of the long-term cluster initiative for the region's new media industry has been the outcome of a close collaboration between policy actors, universities and private companies, transforming Scania into a hot spot of the Swedish new media sector.

Also in the case of the Oslo Cancer Cluster, public policy has been vital for the development of a cluster of cancer medicine firms, but the basis lays in policy to develop science-based knowledge to treat cancer; that is, through science policy to support basic research at University of Oslo and the university hospitals in the Oslo region. However, as funding of basic research is a main responsibility of the public sector, this emphasizes the strategic role of public policy in cluster promotion in general, and for new path creation specifically. The same is the case for the original development of the ICT cluster in Scania in the 1980s, located in the IDEON science park in Lund, where Ericsson developed mobile phones in close research collaboration with Lund Technical University.

The importance of basic research is strategic in the case of new path creation as it requires highly specialized scientific knowledge to become successful. The historical roots of the Oslo Cancer Cluster documented in this chapter illustrate this clearly. However, even if such scientific knowledge (that is, exploration capacity) is a necessary condition for new path creation, the sufficient condition is represented by also having access to exploitation capacity to succeed in commercializing the scientific results. In this respect, Norway and Oslo have a serious drawback due to lack of such exploitation capacity. The large firms that once existed in the region, Nycomed Amersham and Hydro Pharma, are not present anymore and - even if indirectly they still have an impact through the experience and knowledge of previous employees, of which some have become entrepreneurs - the region is characterized by a lack of exploitation capacity, which clearly slows down the route to commercialization. Thus, characteristically, the Oslo Cancer Cluster is still primarily an emergent cluster with respect to exploitation and products on the market. However, there are signs of new types of entrepreneurs - for example, academic and institutional entrepreneurs - as well as new foreign direct investments (FDIs) that have taken on the task of expanding the exploitation capacity in the region.

In general, however, the OCC shows how costly and long-term a strategy of new path creation is, compared to a strategy of path renewal based on combining knowledge bases, which produces results in the form of job creation and new firm formation much faster. This represents important lessons for those policymakers and practitioners responsible for designing a regional development strategy using a cluster approach specifically, in addition to the general message of this chapter of the strategic role public 
policy on different spatial levels plays in implementing and supporting a cluster-based policy strategy for regional development.

\section{REFERENCES}

Asheim, B.T. (2007), Differentiated knowledge bases and varieties of regional innovation systems, Innovation: The European Journal of Social Science Research 20(3), 223-241.

Asheim, B.T. and M. Gertler (2005), The geography of innovation: regional innovation systems, in J. Fagerberg, D. Mowery and R. Nelson (eds.), The Oxford Handbook of Innovation, Oxford: Oxford University Press, pp. 291-317.

Asheim, B.T., P. Cooke and R. Martin (2006), Clusters and Regional Development: Critical Reflections and Explorations, London and New York: Routledge.

Asheim, B.T., R. Boschma and P. Cooke (2011), Constructing regional advantage: platform policies based on related variety and differentiated knowledge bases, Regional Studies 45(7), 893-904.

Asheim, B.T., M.M. Bugge, L. Coenen and S. Herstad (2013), What does evolutionary economic geography bring to the policy table? Reconceptualising regional innovation systems, Papers in Innovation Studies, No. 2013/5, CIRCLE, Lund University.

Belussi, F. and S.R. Sedita (2009), Life cycle vs. multiple path dependency in industrial districts, European Planning Studies 17(4), 505-528.

Bergman, E.M. (2008), Cluster life-cycles: an emerging synthesis, in C. Karlsson (ed.), Handbook of Research on Cluster Theory, Cheltenham: Edward Elgar Publishing, pp. 114-132.

Boschma, R. (2015), Towards an evolutionary perspective on regional resilience, Regional Studies 49(5), 733-751.

Boschma, R. and D. Fornahl (2011), Cluster evolution and a roadmap for future research, Regional Studies 45(10), 1295-1298.

Boschma, R. and K. Frenken (2011), Technological relatedness, related variety and economic geography, in P. Cooke, B. Asheim, R. Boschma, R. Martin, D. Schwartz and F. Tödtling (eds.), Handbook of Regional Innovation and Growth, Cheltenham: Edward Elgar Publishing, pp. 187-197.

Braczyk, H.-J., P. Cooke and M. Heidenreich (1998), Regional Innovation Systems: The Role of Governance in a Globalized World, London: UCL Press.

Cooke, P. (2002), New media and new economy cluster dynamics, in L.A. Lievrouw and S. Livingstone (eds.), Handbook of New Media: Social Shaping and Social Consequences of ICTs, London: Sage, pp. 287-303.

Cooke, P., B.T. Asheim, J. Annerstedt, J. Blažek, R. Boschma, D. Brzica, A. Dahlstrand Lindholm, J. del Castillo Hermosa, P. Laredo, M. Moula and A. Piccaluga (2006), Constructing Regional Advantage: Principles - Perspectives - Policies, www. dime-eu.org/files/active/0/regional_advantage_FINAL.pdf, accessed 24 October 2015.

EC (2012), Guide to Research and Innovation Strategies for Smart Specialisations (RIS3), Brussels: European Commission.

Enright, M. J. (2003), Regional clusters: what we know and what we should know, in J. Bröcker, D. Dohse and R. Soltwedel (eds.), Innovation Clusters and Interregional Competition, Berlin and Heidelberg: Springer, pp. 99-129. 
Furre, H. and A. Flatnes (2013), Evaluering av NCE Oslo Cancer Cluster, Kristiansand: Oxford Research AS.

Grabher, G. (2002), The project ecology of advertising: tasks, talents and teams, Regional Studies 36(3), 245-262.

Heed, J., S. Munkhammar, I. Rydell, K. Windell and L. Andersson (2008), Från Möten Till Tillväxt? Effektutvärdering av KK-Stiftelsens Satsning på Upplevelseindustrin, Stockholm: KK-Stiftelsen.

Isaksen, A. (2009), Innovation dynamics of global competitive regional clusters: the case of the Norwegian centres of expertise, Regional Studies 43(9), 1155-1166.

Isaksen, A. (2011), Cluster evolution, in P. Cooke, B. Asheim, R. Boschma, R. Martin, D. Schwartz and F. Tödtling (eds.), Handbook of Regional Innovation and Growth, Cheltenham: Edward Elgar Publishing, pp. 293-302.

Isaksen, A. and M. Nilsson (2013), Combining innovation policy: linking scientific and practical knowledge in innovation systems, European Planning Studies 21(12), 1919-1936.

Isaksen, A. and M. Trippl (2016), Path development in different regional innovation systems: a conceptual analysis, in M. Parilli, D. Fitjar and A. Rodriguez-Pose (eds.), Innovation drivers and regional innovation strategies, London: Routledge, pp. 66-84.

Jensen, M. B., B. Johnson, E. Lorenz and B.-Å. Lundvall (2007), Forms of knowledge and modes of innovation, Research Policy 36(5), 680-693.

Kiese, M. (2005), Clusterpolitik in Deutschland: Ein wirtschaftsgeographischer Vergleich aus institutioneller und politisch-ökonomischer Perspektive, Habilitationsschrift, Hannover: Leibnitz Universität Hannover.

Koschatzky, K. (2012), Cluster quo vadis? The future of the cluster concept, Fraunhofer ISI Working Papers Firms and Regions, No. R1/2012, Karlsruhe: Fraunhofer ISI.

Laestadius, S. (2007), Vinnväxtprogrammets teoretiska fundament, in S. Laestadius, C. Nuur and H. Ylinenpää (eds.), Regional växtkraft i en global ekonomi. Det svenska Vinnväxtprogrammet, Stockholm: Santerus Academic Press, pp. 27-56.

Landabaso, M. (2014), Guest editorial on research and innovation strategies for smart specialisation in Europe, European Journal of Innovation Management 17(4), 378-389.

Lie, E. (2005), Oljerikdommer og internasjonal ekspansjon: Hydro 1977-2005, Oslo: Pax.

Lievrouw, L.A. and S. Livingstone (2002), Handbook of New Media: Social Shaping and Social Consequences of ICTs, London: Sage.

Lorenz, E. and B.-Å. Lundvall (2006), How Europe's Economies Learn: Coordinating Competing Models, Oxford: Oxford University Press.

Lorenzen, M. (2005), Editorial: why do clusters change?, European Urban and Regional Studies 12(3), 203-208.

Lundvall, B.-A. (2008), National innovation systems - analytical concept and development tool, Industry \& Innovation 14(1), 95-119.

Marshall, A. (1890), Principles of Economics, London: Macmillan.

Martin, R. and J. Moodysson (2011), Innovation in symbolic industries: the geography and organization of knowledge sourcing, European Planning Studies 19(7), 1183-1203.

Martin, R. and J. Moodysson (2013), Comparing knowledge bases: on the geography and organisation of knowledge sourcing in the regional innovation system of Scania, Sweden, European Urban and Regional Studies 20(2), 170-187. 
Martin, R. and P. Sunley (2003), Deconstructing clusters: chaotic concept or policy panacea?, Journal of Economic Geography 3(1), 5-35.

Martin, R. and P. Sunley (2006), Path dependence and regional economic evolution, Journal of Economic Geography 6(4), 395-437.

Martin, R. and P. Sunley (2011), Conceptualizing cluster evolution: beyond the life cycle model?, Regional Studies 45(10), 1299-1318.

Martin, R. and M. Trippl (2014), System failures, knowledge bases and regional innovation policies, disP: The Planning Review 50(1), 24-32.

Martin, R. and M. Trippl (2015), Cluster evolution, regional innovation systems and knowledge bases: the development and transformation of the ICT Cluster in southern Sweden, Papers in Innovation Studies, No. 2015/24, Lund: CIRCLE, Lund University.

Menzel, M.-P. and D. Fornahl (2010), Cluster life cycles - dimensions and rationales of cluster evolution, Industrial and Corporate Change 19(1), 205-238.

Morgan, K. (2013), Path dependence and the state: the politics of novelty in old industrial regions, in P. Cooke (ed.), Reframing Regional Development: Evolution, Innovation, Transition, London: Routledge, pp. 318-340.

Nicolaysen, N. (2013), Den nye oljen - en voksende kreftindusti, Master's thesis, Grimstad: University of Agder.

OECD (2013a), Innovation-Driven Growth in Regions: The Role of Smart Specialisation, Paris: Organisation for Economic Co-operation and Development.

OECD (2013b), OECD Reviews of Innovation Policy: Sweden 2012, Paris: Organisation for Economic Co-operation and Development.

Porter, M.E. (1990), The Competitive Advantage of Nations, New York: Free Press.

Porter, M.E. (1998), Clusters and the new economics of competition, Harvard Business Review 76(6), 77-90.

Reve, T. and A. Sasson (2012), Et kunnskapsbasert Norge, Oslo: Universitetsforlaget.

Simmie, J. and R. Martin (2010), The economic resilience of regions: towards an evolutionary approach, Cambridge Journal of Regions, Economy and Society $3(1), 27-43$.

Skålholt, A. and T. Thune (2013), Coping with economic crises - the role of clusters, European Planning Studies 22(10), 1993-2010.

Skårderud, F. (2007), Aristokratisk og folkelig. Om Radiumhospialets historie, in K.O. Åmås (ed.), Livet med kreft, Oslo: Aschehoug, pp. 200-230.

Strambach, S. and B. Klement (2013), Exploring plasticity in the development path of the automotive industry in Baden-Württemberg: the role of combinatorial knowledge dynamics, Zeitschrift für Wirtschaftsgeographie 57(1-2), 67-82.

Tödtling, F. and M. Trippl (2005), One size fits all? Towards a differentiated regional innovation policy approach, Research Policy 34(8), 1203-1219.

Trippl, M., M. Grillitsch, A. Isaksen and T. Sinozic (2015), Perspectives on cluster evolution: critical review and future research issues, European Planning Studies 23(10), 2028-2044.

Van den Berg, L., E. Braun and W. van Winden (2001), Growth clusters in European cities: an integral approach, Urban Studies 38(1), 185-205.

Vesterbekkmo, S.M. (2010), Verdivurdering av Algeta ASA, Master's thesis, Tromsø: University of Tromsø. 